\title{
HUBUNGAN KOMUNIKASI PETUGAS KESEHATAN DENGAN SELF CARE DIABETES PADA KLIEN DIABETES MELITUS TIPE 2
}

\section{THE RELATIONSHIP BETWEEN HEALTH WORKER COMMUNICATION AND SELF CARE DIABETES IN PATIENT WITH DIABETES MELLITUS TYPE 2}

\author{
Setiyawan \\ Prodi S1 Keperawatan STIKes Kusuma Husada Surakarta \\ etya1025@gmail.com
}

\begin{abstract}
Abstrak
Self care diabetes merupakan hal penting dalam pengelolaan DM tipe 2, komunikasi yang efektif antara petugas kesehatan dengan klien akan mendorong perubahan perilaku perawatan diri yang lebih mandiri dan memberikan dampak pada peningkatan derajad kesehatan yang optimal.Penelitian ini bertujuan untuk mengetahui hubungan komunikasi petugas kesehatan dengan self care diabetes pada klien DM tipe 2 di RSUD Karanganyar. Desain penelitian cross sectional pada 30 responden dengan teknik purposive sampling dan pengumpulan data menggunakan kuesioner. Analisis data menggunakan korelasi pearson product moment. Hasil analisis uji pearson product moment menunjukkan komunikasi petugas kesehatan berhubungan dengan self care diabetes dengan $p=0.001$ dan $r=0.51$. Perlu dikembangkan edukasi diabetes yang terprogram.
\end{abstract}

Kata kunci: Diabetes Mellitus, Komunikasi, Self Care

\begin{abstract}
Diabetes self care is essential in the management of type 2 diabetes, effective communication between health workers and clients will encourage self-care behavior change to be more independent and have an impact on improving the health. The aimed the study is to determine the relationship of health worker communication with self diabetes care in type 2 diabetes client in Karanganyar Hospital. The reseach was design cross-sectional study on 30 people with purposive sampling and data collection using questionnaires. Analysis of the data using the pearson product moment correlation. The results of test analysis pearson product moment indicates the communication of health workers associated with diabetes self care with $p=0.001$ and $r=0.51$. Need to develop diabetes education programmed.
\end{abstract}

Keywords: Diabetes Mellitus, Communications, Self Care

\section{PENDAHULUAN}

Jumlah kasus diabetes mengalami peningkatan secara signifikan pada sepuluh tahun belakangan ini dan merupakan penyebab kematian keenam diseluruh dunia. Peningkatan jumlah kasus diabetes tersebut akan berdampak terhadap menurunya umur harapan hidup, meningkat angka kesakitan dan berkurangnya kualitas hidup (Nwanko et al, 2010).

Hasil studi pendahuluan di Rumah Sakit Umum Daerah (RSUD) Karanganyar, diketahui bahwa jumlah kasus diabetes melitus untuk rawat inap tahun 2015 berjumlah 436 orang, sedangkan rawat jalan berjumlah 876 kasus. Rata-rata klien berada pada rentang usia 45-64 tahun (Medical Record RS, 2015).

Diabetes melitus tipe 2 merupakan jenis diabetes yang lebih sering terjadi $90-95 \%$ dari semua orang yang menderita diabetes (ADA, 2010). Masalah utama yang dihadapi oleh klien DM tipe 2 adalah peningkatan kadar gula darah yang dapat memicu timbulnya beberapa 
komplikasi baik mikrovaskuler ataupun makrovaskuler (Sousa et al, 2009). Permasalahan lain dari penderita DM tipe 2 adalah masalah psikologis yaitu beban psikologi (stress), respon emosional negatif, cemas, depresi. Masalah sosial dapat muncul pada penderita DM tipe 2 berupa berkurangnya interaksi sosial dan hubungan interpersonal akibat perasaan putus asa. Permasalahan lain yaitu masalah ekonomi terhadap penurunan produktifitas kerja, pendapatan serta pengendalian pada pengobatan DM tipe 2 dalam jangka waktu lama yang berdampak pada ekonomi keluarga (Price \& Wilson, 2005).

Masalah-masalah yang dialami klien DM tipe 2 dapat diminimalkan jika klien memiliki pengetahuan dan kemampuan yang cukup untuk melakukan pengontrolan terhadap penyakitnya dengan melakukan self care. Self care menggambarkan perilaku individu yang dilakukan secara sadar, bersifat universal dan terbatas pada diri sendiri dengan tujuan mengoptimalkan, meningkatkan kemandirian dalam derajad kesehatan (Weiler \& Janice, 2007; Sousa et al, 2009).

Perawat berupaya memandirikan klien DM tipe 2 dalam mengelola penyakitnya agar tercapai pengontrolan gula darah dan pencegahan terhadap komplikasi. Upaya mandiri yang dilakukan oleh klien DM tipe 2 tersebut disebut dengan self care diabetes, yang merupa-kan bagian terintegrasi dari proses keperawatan. Self care diabetes yang dilakukan oleh klien meliputi minum obat secara teratur, melakukan pengaturan makan/diet, melakukan latihan fisik, monitor gula darah secara kontinu dan melakukan perawatan kaki secara teratur (Xu Yin, et al, 2008). Peningkatan aktifitas self care diabetes akan berdampak terhadap peningkatan status kesehatan, karena merupakan dasar untuk mengontrol diabetes dan mencegah komplikasi (Xu Yin et al, 2008).

Self care diabetes sangat berguna bagi klien DM tipe 2, tetapi tindakan ini belum konsisten dilakukan oleh beberapa klien DM tipe 2 . Berdasarkan hasil wawancara dengan tiga orang klien DM tipe 2 diketahui dua orang diantaranya bosan minum obat, satu orang pola makannya tidak teratur, dan ketiganya tidak melakukan perawatan kaki dengan alasan tidak mengetahuinya dan petugas kesehatan tidak memberikan penjelasan secara jelas. Hal ini menggambarkan bahwa self care diabetes belum dilakukan secara adekuat.
Komunikasi dalam asuhan keperawatan klien khususnya pada penderita DM tipe 2 memiliki peranan yang penting didalam mencapai tujuan perawatan mandiri (Shigaki et $a l$, 2010). Komunikasi yang efektif antara petugas dengan klien akan mendorong perubahan perilaku perawatan diri yang lebih mandiri dan memberikan dampak pada peningkatan derajad kesehatan yang optimal (Piette et al, 2003). Perawat sebagai petugas kesehatan perlu mengkaji, melakukan komunikasi efektif dan mendalam terhadap beberapa aspek yang berkaitan dengan self care diabetik.

Beberapa faktor yang mempengaruhi perilaku self care diabetes diantaranya adalah pengetahuan tentang diabetes, self efficacy, dukungan keluarga (Xu Yin et al, 2008; Nelson et al, 2007; Bai et al, 2009). Hasil penelitian lain menjelaskan bahwa selain faktor tersebut, sosial ekonomi, aspek emosional, komunikasi, motivasi yang berkaitan dengan perilaku dalam melakukan perawatan diri (Nwanko, 2010; Shigaki et al 2010; Kusniawati, 2011).

Berdasarkan latarbelakang tersebut diatas, penulis tertarik untuk meneliti, "Hubungan antara komunikasi petugas kesehatan dengan self care diabetes pada klien DM tipe 2 di RSUD Karanganyar".

Tujuan dari penelitian ini adalah mengetahui hubungan antara komunikasi petugas kesehatan dengan self care diabetes pada klien DM tipe 2.

\section{METODE}

Penelitian ini merupakan penelitian corelational dengan desain penelitian cross sectional. Penelitian ini dilakukan di unit rawat jalan/ poliklinik RSUD Karanganyar. Sampel pada penelitian ini adalah 30 responden dengan menggunakan teknik purposive sampling yaitu klien DM tipe II di RSUD Karanganyar.

Instrumen yang digunakan dalam pengumpulan data menggunakan kuesioner untuk mengetahui komunikasi petugas kesehatan dan pengukuran self care diabetes. Kuesioner komunikasi petugas kesehatan merujuk pada kuesioner yang telah valid dan reliable dari penelitian Kusniawati (2011) sedangkan pengukuran self care diabetes menggunakan pengukuran aktivitas self care diabetes (The summary of Diabetes SelfCare Activities/ SDSCA) yang dikembangkan oleh Toobert, et al 2010). 
Teknik analisis data menggunakan uji pearson product moment dengan tingkat kepercayaan 95\% untuk mengetahui hubungan antara komunikasi petugas kesehatan dengan self care diabetes pada klien DM tipe 2.

\section{HASIL PENELITIAN DAN PEMBAHASAN}

Hasil analisis univariat karakteristik responden yang menggambarkan masing-masing variabel usia, jenis kelamin, dan lama menderita DM, diketahui bahwa sebagian besar responden berjenis kelamin perempuan yaitu $60 \%$, sisanya adalah laki-laki dan rerata usia responden adalah 54 tahun, sedangkan rata-rata lama menderita responden adalah 7.1 tahun dengan hasil estimasi interval antara 6.0 sampai 8.2 tahun.

Hasil analisis univariat pada komunikasi petugas kesehatan dan self care diabetes (pada tabel 1 dan 2) serta hasil analisis bivariat antara komunikasi petugas kesehatan dengan self care diabetes (pada tabel 3) adalah sebagai berikut:

Tabel 1. Distribusi Responden Komunikasi Petugas Kesehatan RSUD Karanganyar (n:30)

\begin{tabular}{lcccc}
\hline Variabel & Mean & SD & Minimal-Maximal & $95 \%$ CI \\
\hline $\begin{array}{l}\text { Komunikasi petugas } \\
\text { kesehatan }\end{array}$ & 1.5 & 0.5 & $0.1-3$ & $1.4-1.6$ \\
\hline
\end{tabular}

Tabel 2. Distribusi Responden Self Care Diabetes RSUD Karanganyar (n:30)

\begin{tabular}{llcccc}
\hline No. & Variabel & Mean & SD & Minimal-Maximal & 95\% CI \\
\hline 1. & Diet & 5.3 & 1.2 & $0.4-6$ & $4.8-5.7$ \\
2. & Latihan fisik & 4.3 & 2.4 & $0-6$ & $3.4-5.2$ \\
3. & Monitoring gula darah & 1.0 & 0.2 & $1-2$ & $0.8-1.2$ \\
4. & Minum obat secara teratur & 5.9 & 1.2 & $0-7$ & $5.6-6.2$ \\
5. & Perawatan kaki & 3.7 & 2.3 & $0-6$ & $3.2-4.2$ \\
6. & Total self care diabetes & 4.9 & 1.2 & $1.2-5.5$ & $4.7-5.2$ \\
\hline
\end{tabular}

Tabel 3. Analisis Hubungan Komunikasi Petugas Kesehatan dengan Self Care Diabetes RSUD Karanganyar (n: 30)

\begin{tabular}{lllll}
\hline Variabel & $\mathrm{R}$ & $\mathrm{R}^{2}$ & Persamaan & $p$ value \\
\hline $\begin{array}{l}\text { Komunikasi petugas } \\
\text { kesehatan }\end{array}$ & 0.51 & 0.26 & $\begin{array}{l}\text { Self care diabetes= 3.04 }+1.11 \\
\text { komunikasi petugas kesehatan }\end{array}$ & 0.001 \\
\hline
\end{tabular}

Pada tabel 1, rerata komunikasi petugas kesehatan dalam hal pemberian informasi/ pendidikan kesehatan terkait aktifitas self care diabetes adalah 1.5 , berdasarkan nilai rata-rata dan disesuaikan dengan skala instrumen dalam penelitian ini dapat disimpulkan bahwa rata-rata komunikasi petugas kesehatan dalam hal pemberian informasi/ pendidikan kesehatan terkait aktifitas self care diabetes cenderung sering dilakukan. Hasil estimasi interval dapat disimpulkan bahwa rata-rata klien DM tipe 2 yang berobat cenderung sering mendapatkan pendidikan kesehatan tentang self care diabetes dari petugas kesehatan.
Hasil analisis self care diabetes pada table 2 didapatkan bahwa rata-rata responden melakukan pengaturan diet 5.3 hari dalam seminggu, dengan estimasi interval 4.8 hari sampai 5.7 hari dalam seminggu. Rata-rata responden melakukan latihan fisik adalah 4.3 hari dalam seminggu, rata-rata responden melakukan monitoring gula darah 1.0 hari dalam seminggu, minum obat secara teratur 5.9 hari dalam seminggu dan ratarata responden melakukan aktifitas self care diabetes 4.9 hari dalam seminggu.

Analisis hubungan komunikasi petugas kesehatan dengan self care diabetes menunjukan bahwa semakin tinggi komunikasi petugas kesehatan dalam hal memberikan pendidikan 
kesehatan tentang aktifitas tentang self care diabetes maka aktifitas self care diabetes semakin meningkat dan hubungan tersebut menunjukan hubungan yang kuat (r: 0.51). Hasil uji statistik menunjukkan bahwa terdapat hubungan yang signifikan antara komunikasi petugas kesehatan dengan self care diabetes $(\mathrm{p}=0.001)$.

Berdasarkan hasil penelitian dan analisis data menunjukkan bahwa komunikasi petugas kesehatan dalam hal pemberian informasi/ pendidikan kesehatan tentang self care cenderung sering dilakukan. Komunikasi petugas kesehatan dalam hal pemberian informasi/ pendidikan kesehatan terkait aktifitas self care diabetes merupakan hal yang penting dilakukan dalam interaksi antara klien DM tipe 2 dengan petugas kesehatan di dalam tatanan pelayanan kesehatan.

Komunikasi petugas kesehatan terkait dengan pelayanan yang diberikan kepada klien diabetes adalah pemberian informasi/ pendidikan kesehatan terkait aktifitas self care diabetes yang meliputi aktifitas diet atau pengaturan pola makan, latihan fisik atau olahraga, monitoring gula darah, minum obat secara teratur dan perawatan kaki. Informasi tersebut harus secara adekuat disampaikan kepada klien agar klien memiliki pemahaman yang luas berkaitan dengan penyakit yang dialaminya (Piette et al, 2003)

Petugas kesehatan harus melakukan evaluasi terhadap pendidikan kesehatan terkait self care diabetes yang telah diberikan kepada klien untuk memastikan bahwa klien telah memahami apa yang telah disampaikan tersebut. Diabetes merupakan penyakit kronis yang mengharuskan penderitanya untuk melakukan manajemen self care diabetes secara kontinu sehingga hal-hal yang berkaitan dengan self care diabetes tersebut harus selalu dipantau agar tujuan perawatan dapat tercapai dengan baik.

Kenyataanya program petugas kesehatan/ edukasi diabetes belum terprogram secara khusus, dimana belum ada jadwal khusus untuk hari edukasi terhadap klien DM, sedangkan edukasi itu merupakan hal penting dalam memberikan asuhan keperawatan terhadap klien DM. Edukasi yang berjalan saat ini hanya terbatas saat klien control ke rumah sakit, sehingga dengan waktu yang relative singkat hanya sedikit informasi yang dapat disampaikan kepada klien dan bersifat individual. Selain itu belum ada penggunaan media audiovisual yang dapat menunjang dalam proses pemberian informasi terhadap klien.
Analisis hubungan antara komunikasi petugas kesehatan dengan self care diabetes pada penelitian ini menunjukkan bahwa terdapat hubungan yang signifikan antara komunikasi petugas kesehatan terhadap self care diabetes. Semakin tinggi frekuensi komunikasi petugas kesehatan dalam hal pemberian informasi atau pendidikan kesehatan tentang self care diabetes maka aktifitas self care diabetes semakin meningkat.

Hasil penelitian ini mendukung pendapat Piette et al (2003) yang menjelaskan bahwa komunikasi petugas kesehatan merupakan hal penting untuk mencapai self care diabetesyang efektif. Hasil yang didapat menunjukan bahwa dengan meningkatkan komunikasi petugas kesehatan yang spesifik berhubungan dengan diabetes akan meningkatkan kemungkinan klien untuk melakukan aktifitas self care diabetes, yaitu terjadi peningkatan untuk melakukan perawatan kaki dan pengaturan pola makan.

Hasil penelitian ini juga mendukung penelitian yang dilakukan oleh Heisler et al (2007) dan Xu Yin et al (2008) yang menjelaskan bahwa komunikasi petugas kesehatan memiliki hubungan yang signifikan dengan perawatan diri, komunikasi petugas kesehatan yang efektif merupakan hal penting dan factor yang paling berpengaruh terhadap self care diabetes. Komunikasi petugas kesehatan yang baik tidak hanya memeberiakn pemahaman yang penting bagi klien tentang penatalaksanaan self care diabetes yang harus dijalankan tetapi juga dapat meningkatkan kepercayaan diri (Kusniawati, 2011).

Peningkatan komunikasi petugas kesehatan selain berdampak pada self care diabetesjuga berdampak pada kepuasan dan kepatuhan terhadap perencanaan pengobatan serta meningkatkan pencapaian hasil dalam pengelolaan diabetes. Petugas kesehatan memiliki peran terdepan dalam membantu klien mengelola kondisi kronik penyakitnya untuk meningkatkan status kesehatan dan kualitas hidup (Heisler et al, 2007 dalam Kusniawati, 2011).

Komunikasi petugas kesehatan yang terkait dengan pendidikan kesehatan dapat meningkatkan ketrampilan self care diabetes dan penyesuaian terhadap diabetes serta berdampak terhadap kesehatan emosional, mengurangi kecemasan dan depresi. Pendidikan kesehatan terkait dengan aktifitas self care diabetes harus selalu dipertahankan dalam setiap kunjungan yang dilakukan dengan tujuan agar klien selalu 
mengingat dan mematuhi hal-hal apa saja yang harus dilakukan oleh klien dirumah agar tercapai kadar gula darah yang terkontrol dan meminimalkan komplikasi akibat diabetes (Kusniawati, 2011).

Klien diabetes secara individual memiliki peran utama dalam upaya mencapai tujuan self care bagi dirinya. Petugas kesehatan dapat berkontribusi dalam proses tersebut dengan cara memberikan informasi yang dibutuhkan oleh klien untuk mengatasi masalah yang dihadapinya, membantu menetapkan tujuan agar tercapai perubahan perilaku dan memberikan dukungan emosional secara berkesinambungan. Hal ini dapat meningkatkan kemampuan klien jangka panjang untuk mempertahankan self care yang efektif dan membantu klien menghindari rasa bosan yang biasa dialami oleh klein diabetes (Kusniawati, 2011).

Penanganan diabetes yang dilakukan secara terpadu dengan melibatkan dokter ahli metabolicendokrin, ahli gizi, petugas laboratorium dan perawat yang memiliki ketrampilan merawat diabetes serta melakukan edukasi akan meningkatkan kualitas asuhan yang diberikan kepada klien diabetes, selain itu kerjasama antar tim kesehatan dapat memberikan dukungan secara intensif untuk membantu klien menetapkan dan melakukan evaluasi terhadap pencapaian tujuan self manajemen diabetes (Peimani et al, 2010).

\section{SIMPULAN}

Terdapat hubungan yang signifikan antara komunikasi petugas kesehatan terhadap self care diabetes pada Klien DM tipe 2. Perlunya diselengarakan program edukasi pendidikan kesehatan terkait dengan self care diabetes terutama tentang perawatan kaki yang terjadwal secara khusus dan disediakanya media audiovisual yang dapat menunjang pemberian informasi kesehatan tentang self care diabetes yang dapat dimanfaatkan oleh klien saat klien menunggu panggilan diruang tunggu.

\section{DAFTAR PUSTAKA}

American Diabetes Assosiation. 2010. Standards of medical care in diabetes. Diabetes Care.

Bai, Y.L, Chiou, C.P \& Chang, Y.Y. 2009. Self care behaviour and related factor in older people with type 2 diabetes. Journal of Clinical Nursing.

Heisler, M., Cole, I., Weir, D., Ker, E.A., \&Hayward, R.A. 2007. Does physician communication influence older patient's diabetes self management and glycemic control? Result from the health and retirement study (HRS). Journal Gerontology, 62A (12).

Kusniawati. 2011. Analisis Faktor yang Berkontribusi terhadap Self Care Diabetes pada klien Diabetes Melitus Tipe 2 di Rumah Sakit Umum Tangerang. Tesis. Diunduh dari http://lontar.ui. ac.id/file?file $=$ digital $/ 20281676$ T\%20Kusniawati.pdf.

Nelson, K.M., McFarland, L., Reiber, G., 2007. Factor influencing desease self management among veterans with diabetes and poor glycemic control. Society of General internal Medicine. 22.

Nwanko, C.H, Nandy, B., \& Nwako, B.O. 2010. Factor influencing diabetes managemen outcome among patients attending goverment health facilities in South East, Nigeria. International Journal of Tropical Medicine, 5 (2). 28-36.

Peimani, M., Tabatabei M, \& Pajouhi, M. 2010. Nurse' role in diabetes care: review. Irian Journal of Diabetes and Lipid Disorder, 9.

Piette, J.D., Schillinger, D., Potter, M.B., Heisler, M. 2003. Dimensions of patient-provider comunication and diabetes self care in an ethnically diverse population. Journal of General Internal Medicine, 18.

Price, S.A., \& Wilson, W.M. 2005. Pathofisiologi Konsep Klinik Proses-Proses Penyakit. Cetakan ke-2. Jakarta. EGC.

Shigaki, C., Kruse, R.L, Mehr, D., Sheldon, K.M., Bin G., Moore, C. 2010. Motivation and diabetes self management. Journal of Psycology, 6 (3). 
PROFESI, Volume 14, Nomor 1, September 2016

Sousa, V.D, Hartman, S.W., Miller, E.H., \& Carroll, M.A. 2009. New measure of diabetes self care agency, diabetes self efficacy, and diabetes self management for insulin-treath individual with type 2 diabetes. Journal of Clinical Nursing, 18.

Toobert, D.J., Hampson, S.E., \& Glasgow, R.E. 2010. The summary of diabetes self care activities measure. Diabetes Care, 23 (7).
Weiler, D.M., \& Janice, D.C. 2007. Diabetes self managemen in the migrant Latino Population. Hispanic Health Care Internatioanal, 5 (1).

Xu Yin, Toobert, D., Savage, C., Pan, W., Whimer, K. 2008. Factor influencing diabetes self managemen in Chinese people with type 2 diabetes. Research in Nursing \& Health, 31. 